УДК $630 * 232.1$

ЭКОЛОГО-ХОЗЯЙСТВЕННЫЙ ПОТЕНЦИАЛ СУБТРОПИЧЕСКИХ РАСТЕНИЙ ДЛЯ ИСКУССТВЕННЫХ СУХОСТЕПНЫХ НАСАЖДЕНИЙ МНОГОЦЕЛЕВОГО НАЗНАЧЕНИЯ

\author{
Свинцов И.П., Хужахметова А.Ш., Семенютина В.А., Семенютина А.В.
}

ФГБНУ «Федеральный научный цеентр агроэкологии, комплексных мелиораций и защитного лесоразведения» Российской академии наук, Волгоград, е-mail: vnialmi@yandex.ru

\begin{abstract}
Одним из важнейших направлений биологической науки является разработка теоретических основ целесообразного использования природных растительных ресурсов, отличающихся разнообразием. Обогащением видового состава искусственных насаждений в засушливых условиях достигается их многофункциональность и повышение биоресурсного потенциала земель сельскохозяйственного и несельскохозяйственного назначения. Актуальность этих вопросов в связи с глобальными изменениями климата особенно возрастает на малолесных территориях. Цель исследований - определить эколого-хозяйственный потенциал субтропических растений (на примере унаби - Zizyphus jujuba, фундука - Corylus pontica) для обогащения деградированных ландшафтов сухостепного региона. Использованы морфологические, эколого-физиологические, биохимические методы исследований и современное оборудование (кондуктомер S230Kit, устройство Dualex Scientific, климатическая камера КХТВ-0,22). На примере субтропических растений (шести сортов унаби $-Z$. jujuba и трех сортов фундука - C. pontica) приведены параметры эколого-хозяйственного потенциала сортов для условий каштановых почв. Дана характеристика погодных условий за 20-летний период эксперимента по интродукции и выделены наиболее деструктивные их сочетания (оттепели зимой с резким снижением температуры при отсутствии снежного покрова, засухи), повлиявшие на сохранность, таксационные характеристики и репродуктивную способность опытных растений. При определении эколого-хозяйственного потенциала сортов, как научного прогноза, выявлены критерии признаков и их сочетания, которыми должны обладать растения, обеспечивающие необходимый уровень адаптации к стресс-факторам (морозы, засухи, засоление), продуктивности и других научно обоснованных прогнозных сочетаний оптимальных признаков для многоцелевого использования субтропических кустарников для искусственных сухостепных насаждений.
\end{abstract}

Ключевые слова: эколого-хозяйственный потенциал, субтропические растения, Zizyphus jujuba, Corylus pontica, искусственные насаждения, кустарники многоцелевого назначения, обогащение дендрофлоры, адаптация, каштановые почвы

\title{
ECOLOGICAL AND ECONOMIC POTENTIAL OF SUBTROPICAL PLANTS FOR ARTIFICIAL STEPPE OF MULTIPURPOSE PLANTATIONS
}

\author{
Svintsov I.P., Khuzhakhmetova A.Sh., Semenyutina V.A., Semenyutina A.V. \\ Federal Scientific Centre of Agroecology, Complex Melioration and Protective Afforestation \\ of Russian Academy of Sciences, Volgograd, e-mail: vnialmi@yandex.ru
}

One of the most important areas of biological science is the development of the theoretical foundations for rational use of natural plant resources that are diverse. By enriching the species composition of artificial plantations in arid conditions, their multifunctionality and increase of the bioresource potential of agricultural and nonagricultural lands is achieved. The relevance of these issues in connection with global climate change is increasing, particularly in low forest areas. The objective of this research is to determine ecological and economic potential of subtropical plants (using the example of unabi - Zizyphus jujuba, hazelnuts - Corylus pontica) to enrich the degraded landscapes of the dry-steppe region. Morphological, ecological, physiological, biochemical research methods and modern equipment were used (conductometer S230Kit, device Dualex Scientific, climatic chamber KHTV-0.22). Using the example of subtropical plants (six varieties of unabi - Zizyphus jujuba and three varieties of hazel-nuts - Corylus pontica) parameters of the ecological and economic potential of the varieties for the conditions of chestnut soils are presented. The characteristic of weather conditions for the 20 -year period of the introduction experiment is given and their most destructive combinations vary (thaw in winter with a sharp decrease in temperature in the absence of snow cover, drought), affecting the safety, taxation characteristics and reproductive ability of experimental plants. In determining ecological and economic potential of varieties as a scientific forecast, criteria of characteristics and their combinations were found that plants should have that provide the necessary level of adaptation to stress factors (frost, drought, salinity), productivity and other scientifically-based predictive combinations of optimal characteristics for multipurpose use of subtropical shrubs for artificial dry steppe plantings.

Keywords: ecological and economic potential, subtropical plants, Zizyphus jujuba, Corylus pontica, artificial plantations, shrubs of multi-purpose, enrichment of dendroflora, adaptation, chestnut soils

Актуальной и общемировой тенденцией в развитии сельского хозяйства является формирование адаптивно-ландшафтных систем земледелия, обеспечивающих увеличение объемов производства экологически безопасной продукции. Эти вопросы остро стоят в регионах со сложными агро- климатическими условиями. Здесь деградированные территории занимают значительные площади и нуждаются в создании искусственных лесоплодовых насаждений с участием адаптированного селекционного ассортимента многоцелевого назначения, устойчивых к стресс-факторам [1]. 
Учитывая современные вызовы, обогащение дендрофлоры малолесных регионов хозяйственно ценными кустарниками является важным инструментом в решении задач национальных проектов «Экология», «Наука» в части региональных программ по сохранению биоразнообразия, формированию комфортной окружающей среды для проживания населения и увеличению природноресурсного потенциала деградированных ландшафтов. Вековой опыт интродукции позволил значительно расширить перспективный ассортимент адаптированных хозяйственно ценных деревьев и кустарников для защитного лесоразведения и озеленения [1]. Некоторые авторы [2, 3] указывают, что под влиянием деструктивных факторов абиотического и биотического характера происходят значительные потери по хозяйственно-экономическим признакам.

Особое место в ассортименте могут занимать устойчивые к комплексу неблагоприятных условий зимнего периода субтропические растения. Среди дикорастущих популяций Нижнего Поволжья унаби (Zizyphus jujuba), лещины (Corylus pontica) отсутствуют [3]. Стратегическое направление обогащения защитных лесных насаждений субтропическими древесными растениями, как и другими, экономически важными видами, заключается в их эффективной эксплуатации и закладке новых площадей из адаптированных видов, форм и сортов.

Цель исследований: определить эколого-хозяйственный потенциал субтропических растений (на примере унаби, фундука) для обогащения деградированных ландшафтов сухостепного региона.

\section{Материалы и методы исследования}

Объекты исследований - видовое и сортовое разнообразие представителей субтропических кустарников (шесть сортов
Zizyphus jujuba и три сорта Corylus pontica), интродуцированных в Волгоградскую область (стационарный опыт с 1998 г., площадь 0,30 га, площадь питания 24,0 м², каштановые и светло-каштановые почвы).

Учитывая специфику выполняемых функций искусственных лесных насаждений в Нижнем Поволжье, к ассортименту деревьев и кустарников предъявляются особые требования для мобилизации и оценки перспектив растений для введения в культуру [1].

Изучение адаптации субтропических растений с учетом лимитирующих факторов, анализа критических периодов для роста, развития, цветения и плодоношения базировались на примере изучения сортов Corylus, Zizyphus juјubа в системе «генотип - среда» [2].

Выявление сходства климатических показателей Волгоградской области и ареалов распространения проводилось на основе сравнительного анализа материалов метеостанций по элементам климата [4]. Эксперимент выполнялся в полевых и лабораторных условиях по методике сортоизучения [5]. Сортовая принадлежность образцов описывалась и фото фиксировалась в онтогенезе. Ежегодно измерялись характеристики: высоты, диаметра, ширины кроны. Степень повреждения растений в зимнее время определялась ежегодно в конце мая по 8-балльной шкале (рис. 1).

В летний период (июнь - август) изучались показатели состояния растений и их водного режима [4]. Достоверность экспериментальных данных подтверждалась статистической обработкой с использованием компьютерных программ. При подборе сортов для искусственных насаждений на первое место выходят параметры: устойчивости к стресс-факторам и таксационных показателей представителей Corylus, Zizyphus jujuba. Предпочтение отводится видам и сортам, у которых минимальны потери при воздействии негативных условий.

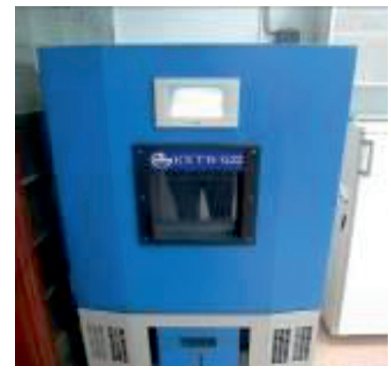

Общий вид климакамеры KXTB $-0,22$

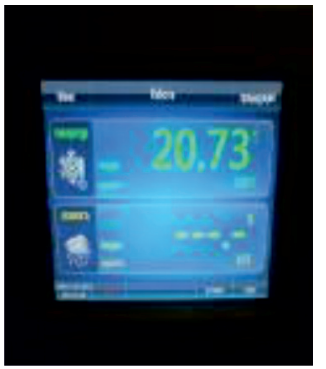

меню температуры и влажности

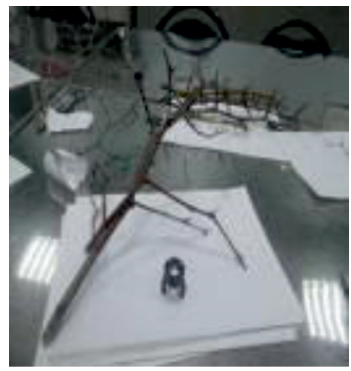

подготовка материала

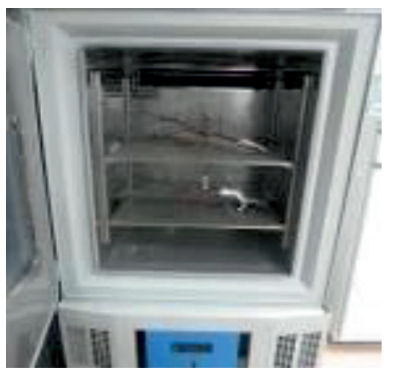

закладка материала

Рис. 1. Фотофиксация процесса промораживания образцов растений 


\section{Результаты исследования} и их обсуждение

Для выделения зимостойких сортов субтропических растений проведен анализ погодных условий в зимние периоды. Он показал, что количество дней с амплитудой суточных температур более $15^{\circ} \mathrm{C}$ составило: один (январь 2006, 2009, 2015; февраль 2006, 2008, 2015, 2017; декабрь 2001, 2002, 2009 ) и два дня (январь 2003, декабрь 2016 г. Для 2006 г. (последняя декада февраля) амплитуда суточных температур составила более $20^{\circ} \mathrm{C}$. По показателям среднемесячной температуры зимнего периода выделены наиболее холодные (январь, февраль 2006, январь 2007 г.) и теплые месяцы (февраль 2002, 2016, декабрь 2010 г.).

Распределение зимних месяцев по количеству дней с положительными и отрицательными суточными температурами воздуха за период 2001-2018 гг. представлено на рис. 2.

Установлены значения низких температур, оказывающие деструктивное влияние на субтропические кустарники в полевых условиях и методом промораживания образцов растений (табл. 1).

Толерантность сортов Zizyphus jujuba к низким температурам

Таблица 1

\begin{tabular}{|c|c|c|c|c|}
\hline \multirow{2}{*}{ Сорт } & \multicolumn{4}{|c|}{ Промораживание при температуре } \\
\cline { 2 - 5 } & \multicolumn{2}{|c|}{$-30^{\circ} \mathrm{C}$} & \multicolumn{2}{c|}{$-37^{\circ} \mathrm{C}$} \\
\cline { 2 - 5 } & $\begin{array}{c}\text { длина } \\
\text { прироста, см }\end{array}$ & $\begin{array}{c}\text { длина подмерзшей } \\
\text { части, см/\% }\end{array}$ & $\begin{array}{c}\text { длина } \\
\text { прироста, см }\end{array}$ & $\begin{array}{c}\text { длина подмерзшей } \\
\text { части, см/\% }\end{array}$ \\
\hline Сочинский & 38 & $7 / 18,42$ & 39 & $15 / 38,46$ \\
\hline Темрюкский & 41 & $7 / 17,07$ & 42 & $18 / 42,86$ \\
\hline Финик & 30 & $12 / 40$ & 29 & $21 / 72,41$ \\
\hline Дружба & 28 & $11 / 39,28$ & 28 & $23 / 82,14$ \\
\hline Южанин & 25 & $16 / 64,0$ & 26 & $24 / 88,46$ \\
\hline Та-ян-цзао & 26 & $18 / 69,23$ & 27 & $24 / 88,89$ \\
\hline
\end{tabular}

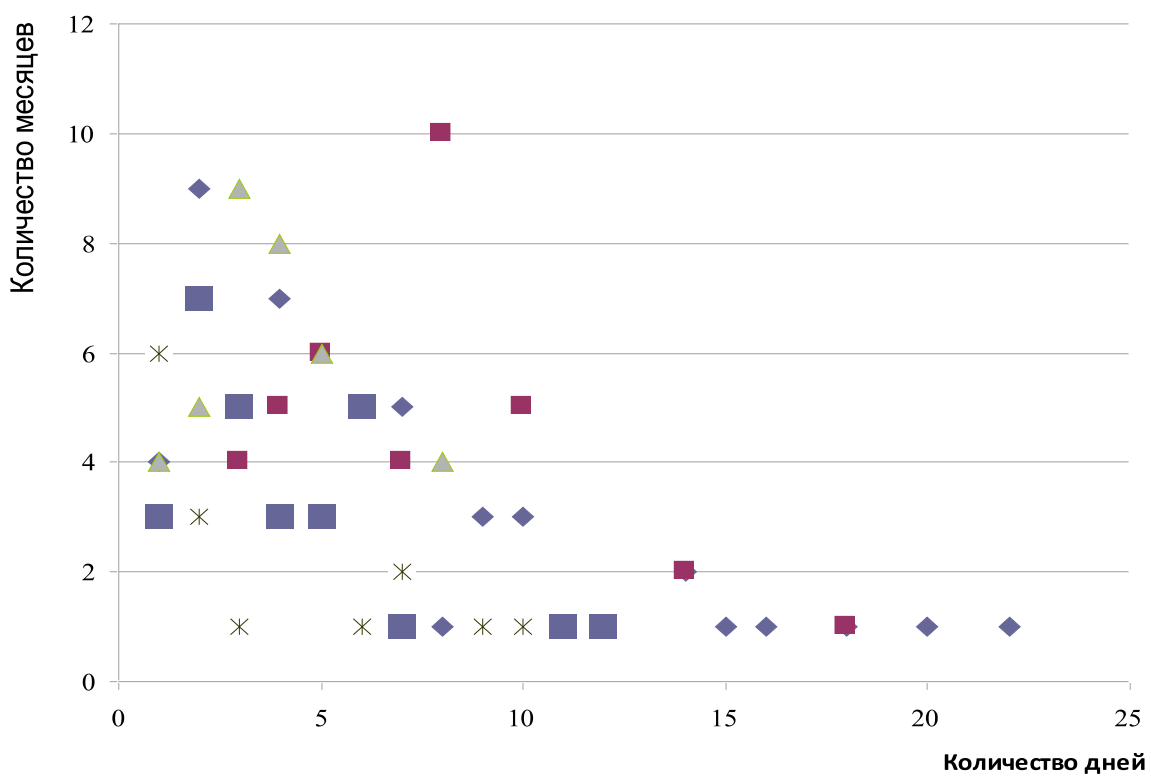

К Количество месяцев со среднесуточной температурой воздуха $\geq 0^{\circ} \mathrm{C}$

Количество месяцев со среднесуточной температурой воздуха ниже $-5^{\circ} \mathrm{C}$

$\triangle$ Количество месяцев со среднесуточной температурой воздуха ниже $-10^{\circ} \mathrm{C}$

Количество месяцев со среднесуточной температурой воздуха ниже $-15^{\circ} \mathrm{C}$

Количество месяцев со среднесуточной температурой воздуха ниже $-20^{\circ} \mathrm{C}$

Рис. 2. Распределение зимних месяиев по показателям положительньх и отрицательных среднесуточных температур воздуха 
Таблица 2

Оценка пигментного комплекса субтропических растительных организмов

\begin{tabular}{|c|c|c|c|c|c|c|}
\hline \multirow{3}{*}{$\begin{array}{c}\text { Растительные } \\
\text { организмы }\end{array}$} & \multicolumn{6}{|c|}{ 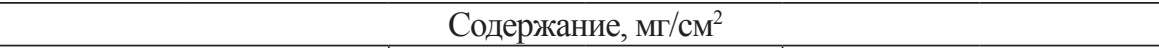 } \\
\hline & \multicolumn{2}{|c|}{ хлорофилл $a+\sigma$} & \multicolumn{2}{|c|}{ флавоноиды } & \multicolumn{2}{|c|}{ антоцианы } \\
\hline & 2017 & 2018 & 2017 & 2018 & 2017 & 2018 \\
\hline $\begin{array}{c}\text { сорта унаби: } \\
\text { мелкоплодные }\end{array}$ & $\frac{23,83 \pm 0,08^{*}}{23,8-23,9}$ & $\frac{23,61 \pm 0,04}{23,1-24,1}$ & $\frac{1,94 \pm 0,03}{1,91-1,97}$ & $\begin{array}{r}1,96 \pm 0,10 \\
1,81-2,04\end{array}$ & $\frac{0,15 \pm 0,001}{0,14-0,15}$ & $\frac{0,15 \pm 0,001}{0,14-0,15}$ \\
\hline среднеплодные & $\frac{28,60 \pm 0,96}{27,6-29,6}$ & $\frac{24,7 \pm 1,34}{24,4-25,1}$ & $\frac{1,85 \pm 0,06}{1,82-1,92}$ & $\frac{1,77 \pm 0,01}{1,76-1,79}$ & $\frac{0,16 \pm 0,006}{0,16-0,17}$ & $\frac{0,13 \pm 0,002}{0,10-0,14}$ \\
\hline крупноплодные & $\frac{31,1 \pm 0,55}{30,5-31,5}$ & $\frac{29,48 \pm 1,14}{28,7-30,8}$ & $\frac{1,87 \pm 0,02}{1,85-1,89}$ & $\frac{1,83 \pm 0,01}{1,76-1,90}$ & $\frac{0,17 \pm 0,009}{0,16-0,18}$ & $\frac{0,13 \pm 0,004}{0,13-0,14}$ \\
\hline $\begin{array}{c}\text { сорта фундука: } \\
\text { Футкурами }\end{array}$ & $\frac{39,94 \pm 1,65}{38,86-41,02}$ & $\frac{29,95 \pm 3,4}{26,79-33,70}$ & $\frac{1,69 \pm 0,09}{1,63-1,76}$ & $\frac{2,05 \pm 0,18}{1,86-2,24}$ & $\frac{0,10 \pm 0,004}{0,09-0,10}$ & $\frac{0,14 \pm 0,003}{0,13-0,15}$ \\
\hline Президент & $\frac{40,75 \pm 1,84}{39,18-42,77}$ & $\frac{29,11 \pm 1,34}{28,26-30,65}$ & $\frac{1,56 \pm 0,06}{1,49-1,61}$ & $\frac{1,73 \pm 0,05}{1,68-1,77}$ & $\frac{0,10 \pm 0,004}{0,09-0,10}$ & $\frac{0,16 \pm 0,004}{0,15-0,16}$ \\
\hline Черкесский-2 & $\frac{25,73 \pm 1,37}{24,19-26,82}$ & $\frac{30,24 \pm 0,50}{30,10-30,36}$ & $\frac{1,92 \pm 0,07}{1,84-1,98}$ & $\frac{2,03 \pm 0,13}{1,89-2,14}$ & $\frac{0,22 \pm 0,01}{0,19-0,26}$ & $\frac{0,12 \pm 0,005}{0,12-0,13}$ \\
\hline \multicolumn{2}{|c|}{ Температура воздуха, ${ }^{\circ} \mathrm{C}$} & & 35,5 & 39,0 & & \\
\hline \multicolumn{2}{|c|}{ Влажность воздуха } & & $16,0 \%$ & $19,0 \%$ & & \\
\hline
\end{tabular}

П р и м е ч а и е. * В числителе - среднее значение и стандартное отклонение значений; в знаменателе - минимальное и максимальное значения.


Рис. 3. Плодовая продуктивность и качественная характеристика сортов фундука 
Пигментный комплекс отвечает за адаптацию организмов к стресс-факторам [6-8]. Установлено, что значения пигментного комплекса (хлорофилл $a+\sigma$, флавоноиды, антоцианы) в течение вегетационного периода варьируют в зависимости от сорта растений $[9,10]$.

Засухоустойчивые сорта характеризуются большей стабильностью пигментного комплекса при относительной влажности воздуха (16-19\%) и повышенных температурах (до $\left.+39^{\circ} \mathrm{C}\right)$ (табл. 2).

Морфологические параметры листьев определяют адаптацию ассимиляционного аппарата к факторам среды. Отмечена тесная связь между количественным содержанием пигментов в листьях растений и их биологическими особенностями (структурная организация листа, толщина, площадь). Установлена разная отзывчивость пигментов на действие стрессфакторов [10].

Оценка репродуктивной способности показала, что Президент и Черкесский-2 отличаются лучшими показателями плодовой продуктивности (рис. 3).

Установлены пределы экологической толерантности субтропических растительных организмов к хлоридному засолению (вегетационный опыт).

\section{Заключение}

Изучение эколого-хозяйственного потенциала Zizyphus jujuba, Corylus и дальнейшее использование полученных результатов позволяет:

- формировать искусственные насаждения разной конструкции (ажурная, плотная, продуваемая) с учетом моделей развития крон изучаемых видов и сортов;

- увеличить количество адаптированных видов (сортов) в рассматриваемых условиях;

- создать дополнительные площади насаждений за счет посадок по границам землепользования; вокруг садов и виноградников, оврагов, на склонах;

- получить дополнительную продукцию (плоды, перга, древесина и др.);

- улучшить почвенное плодородие за счет положительной мелиоративной роли представителей Corylus, Zizyphus jujuba;

- сохранять и развивать коллекционный фонд субтропических культур;

- создание маточных насаждений для производства стандартного посадочного материала для обеспечения нужд и потребностей населения.
Исследования выполнены по теме Государственного задания № 0713-2019-0004 Федерального научного ичентра агроэкологии, комплексных мелиораций и защитного лесоразведения Российской академии наук (ФНЦ агроэкологии РАН).

\section{Список литературы / References}

1. Semenyutina A.V., Podkovyrova G.V., Khuzhakhmetova A.Sh., Svintsov I.P., Semenyutina V.A., Podkovyrov I.Yu. Engineering implementation of landscaping of low-forest regions. International journal of mechanical engineering and technology. 2018. Vol. 9. Issue 10. P. 1415-1422.

2. Рындин А.В., Белоус О.Г., Маляровская В.И., Притула 3.В., Абильфазова Ю.С., Кожевникова А.М. Использование физиолого-биохимических методов для выявления механизмов адаптации субтропических, южных плодовых и декоративных культур в условиях субтропиков России // Сельскохозяйственная биология. 2014. Т. 49. № 3. С. 40-48.

Ryndin A.V., Belous O.G., Malyarovskaya V.I., Pritula Z.V., Abilfazova Yu.S., Kozhevnikova A.M. Physiological and biochemical approaches in studing adaptation mechanisms of subtropical, fruit and ornamental crops grown in russian subtropics // Agricultural Biology. 2014. V. 49. № 3. P. 40-48 (in Russian).

3. Рамазанова 3.Р., Асадулаев 3.М., Омарова П.К. Адаптивные морфолого-анатомические особенности листьев тиса ягодного в условиях предгорного Дагестана // Известия Дагестанского государственного педагогического университета. Естественные и точные науки. 2016. Т. 10. № 2. C. $56-63$.

Ramazanova Z.R., Asadulaev Z.M., Omarova P.K. Adaptive morphological and anatomical features of yew berry leaves in the conditions of foothill Dagestan // Izvestiya Dagestanskogo gosudarstvennogo pedagogicheskogo universiteta. Estestvennye i tochnye nauki. 2016. T. 10. № 2. P. 56-63 (in Russian).

4. Семенютина А.В., Рындин А.В., Махно В.Г., Хужахметова А.Ш., Кравцов И.А. Научно-методические рекомендации по выращиванию фундука в засушливых условиях Нижнего Поволжья. Сочи, 2011. 56 с.

Semenyutina A.V., Ryndin A.V., Makhno V.G., Khuzhakhmetova A.Sh., Kravtsov I.A. Scientific and methodological recommendations on the cultivation of hazelnuts in arid conditions of the Lower Volga region. Sochi, 2011. 56 p. (in Russian).

5. Программа и методика сортоизучения плодовых, ягодных и орехоплодных культур / Под ред. Е.Н. Седова и Т.П. Огольцовой. Орел: ВНИИСПК, 1999. 608 с.

Program and methods of sorting fruit, berry and nut crops / Pod red. E.N. Sedova i T.P. Ogol'tsovoy. Orel: VNIISPK, 1999. 608 p. (in Russian).

6. Bueno J.M., Saez-Plaza P., Ramos-Escudero F., Jimenez A.M., Fett R., Asuero A.G. Analysis and Antioxidant Capacity of Anthocyanin Pigments. Part II: Chemical Structure, Color, and Intake of Anthocyanins. Critical Reviews in Analytical Chemistry. 2012. № 42. P. 126-151. DOI: 10.1080/10408347.2011.632314.

7. Chen M., Blankenship R.E. Expanding the solar spectrum used by photosynthesis. Trends in Plant Science. 2011. № 16. P. 427-431. DOI: 10.1016/j.tplants.2011.03.011

8. Esteban R., Barrutia O., Artetxe U., Fernandez-Marın B., Hernandez A., Garcia-Plazaola J.I. Internal and external factors affecting photosynthetic pigment composition in plants: A metaanalytical approach. New Phytologist. 2015. № 206. P. 268-280. DOI: $10.1111 / \mathrm{nph} .13186$.

9. Семенютина В.А., Свинцов И.П. Динамика содержания пигментного комплекса у растительных организмов в засушливых условиях // Плодоводство и ягодоводство России. 2018. Т. 54. С. 127-131. DOI 10.31676/2073-4948-201854-127-131.

Semenyutina V.A., Svintsov I.P. Dynamics of the content of the pigment complex in plant organisms in arid conditions // Plodovodstvo i yagodovodstvo Rossii. 2018. V. 54. P. 127-131 (in Russian).

10. Penuelas J., Filella I. Visible and near-infrared reflectance techniques for diagnosing plant physiological status. Trends in Plant Science. 1998. № 3. P. 151-156. 